\title{
EL ENSAMBLAJE DEL ARBITRAJE EN LA CONSTITUCIÓN: LAGUNAS DESPUÉS DE 40 AÑOS*
}

\author{
The Arbitration in the Constitution: Gaps after 40 years
}

\author{
María José Carazo-Liébana ${ }^{1}$ \\ Profesora Titular de Derecho Constitucional \\ Universidad de Jaén \\ mjcarazo@ujaen.es \\ http://dx.doi.org/10.18543/ed-67(1)-2019pp165-184 \\ Recibido: 08.01.2019 \\ Aceptado: 21.06 .2019
}

\section{Resumen}

La ausencia de una referencia explícita al arbitraje en el texto constitucional no es óbice para su reconocimiento, hoy plenamente pacífico con apoyo de una jurisprudencia constitucional muy reiterada en este aspecto. No obstante lo anterior, hay aspectos del arbitraje que exigen un análisis desde la perspectiva de las garantías procesalesconstitucionales. En este artículo se plantean cuestiones de importante alcance, tales como si operan o no las garantías del art. 24 de la Constitución en el arbitraje.

\section{Palabras clave}

Arbitraje; tutela judicial; Constitución.

* Cómo citar / Citation 'Chicago-Deusto' (Autor-fecha / Author-date / Lista de referencias / Reference list entries): Carazo-Liébana, María José. 2019. «El ensamblaje del arbitraje en la Constitución: lagunas después de 40 años». Estudios de Deusto 67, n. ${ }^{\circ} 1$ : 165-184. http://dx.doi.org/10.18543/ed-67(1)-2019pp165-184.

${ }^{1}$ Este trabajo ha sido realizado en el marco del Proyecto I+D+I del Plan Nacional: Las entidades locales, sus relaciones y competencias. Realidad, efectos y consecuencias de la racionalización y sostenibilidad financiera en clave nacional y europea (DER201674843-C3-1-R). 


\section{Abstract}

The absence of an explicit reference to the arbitration in the Constitution does not prevent its recognition, which is now fully recognized with the support of a settled constitutional jurisprudence in this regard. However, there are aspects of the arbitration that require an analysis from the perspective of the constitutional procedural guarantees. This article contemplates important issues, such as whether guarantees of art. 24 of the Constitution operate in the arbitration or not

\section{Keywords}

Arbitration; judicial protection; Constitution. 


\begin{abstract}
SUMARIO: I. INTRODUCCIÓN. II. LA ESENCIA DEL ARBITRAJE DESDE EL PRISMA DEL DERECHO CONSTITUCIONAL. III. PRECEPTOS CONSTITUCIONALES APLICABLES AL USO DEL ARBITRAJE. IV. TUTELA JUDICIAL EFECTIVA VERSUS TUTELA ARBITRAL EFECTIVA. 1. El derecho a obtener de los tribunales un pronunciamiento fundado en el Derecho objetivo y a la motivación de la resolución judicial. 2. El derecho a los recursos que las leyes establezcan contra las resoluciones judiciales. 3. El derecho a la ejecución de las resoluciones judiciales. 4. El derecho a la inmodificabilidad de las resoluciones judiciales firmes fuera de los cauces legalmente establecidos al efecto. 5. El derecho a no sufrir indefensión. V. BIBLIOGRAFÍA.
\end{abstract}

\title{
I. INTRODUCCIÓN
}

La institución arbitral puede ser considerada como una gran desconocida desde un punto de vista procesal-constitucional y vamos a argumentarlo con ejemplos que denotan la necesidad de profundizar en la esencia de esta institución a fin de que su uso no implique una merma de derechos por parte de los implicados. Una prueba de lo anterior ha sido la existencia de un contrato de seguro de asistencia jurídica incluido en el art 76 de la Ley 50/1980 de 8 de octubre de contrato de seguro, introducido por la Ley 21/1990 de 19 de diciembre (que adapta el Derecho español a la Directiva 1988/357/CEE, sobre libertad de servicios en seguros distintos al de vida, y de actualización de la legislación de seguros privados) que ha estado vigente 28 años y que recientemente la STC 1/2018 de 11 de enero ha declarado inconstitucional porque otorgaba la posibilidad de acudir al arbitraje por parte del asegurado sin opción a la otra parte de aceptarlo o no, entroncando de forma elemental con la esencia del arbitraje que es la voluntariedad ${ }^{2}$. A estos efectos, nos

${ }^{2}$ La Sala de lo Civil y Penal del Tribunal Superior de Justicia de Cataluña plantea cuestión de inconstitucionalidad sobre el artículo 76 e) de la Ley 50/1980, de 8 de octubre de contrato de seguro por posible vulneración de los artículos 24.1 y $117 \mathrm{CE}$. El precepto cuestionado dispone lo siguiente:

«El asegurado tendrá derecho a someter a arbitraje cualquier diferencia que pueda surgir entre él y el asegurador sobre el contrato de seguro.

La designación de árbitros no podrá hacerse antes de que surja la cuestión disputada.» (el subrayado es nuestro)

Este precepto fue introducido por la Ley 21/1990, de 19 de diciembre para adaptar el Derecho español a la Directiva 1988/357/CEE, sobre libertad de servicios en seguros distintos al de vida, y de actualización de la legislación de seguros privados. A juicio de la Sala de lo Civil y Penal del Tribunal Superior de Justicia de Cataluña que plantea la cuestión de Inconstitucionalidad se vulnera el derecho a la tutela judicial efectiva del 
planteamos cómo ha podido estar vigente este precepto durante tanto tiempo siendo tan evidente su oposición a la esencia del arbitraje, cual es la libre voluntad de las dos partes en conflicto de resolver su controversia por esta forma de justicia alternativa. Y es que como decíamos ab initio el arbitraje es el gran desconocido. No se estudia como asignatura en los planes de Estudio del Grado de Derecho. Tampoco forma parte de ninguna disciplina jurídica en particular a pesar de su carácter transversal. No se estudia su implicación constitucional simplemente porque la Constitución no lo regula (a diferencia de la Constitución de Cádiz). No obstante, lo que sí regula la Constitución es el derecho a la tutela judicial efectiva y ésta entronca directamente con el arbitraje por cuanto se permite que las partes puedan renunciar a la tutela judicial para la resolución arbitral del conflicto. Ahora bien, las partes deben aceptar el laudo arbitral por su efectos de cosa juzgada y ahí es donde viene el problema. ¿Quedan las partes desasistidas en sus derechos del art. 24 de la Constitución (en adelante CE)? Se podría considerar, en una primera aproximación, que la respuesta es negativa porque siempre está la posibilidad del recurso de anulación recogido en el art. 24 de la Ley de Arbitraje. Pero si profundizamos en este recurso nos daremos cuenta que los supuestos del mismo son limitados y meramente formales.

Nos preocupa que hoy en día se está generalizando la opción por la solución arbitral de conflictos para descargar a los tribunales de justicia. Pero hay que subrayar que esa tendencia podría tener efectos «secundarios» o «colaterales» para el ciudadano. No debemos olvidar que es el art. $24 \mathrm{CE}$ es efectivamente un derecho de configuración legal, si bien nunca se podrán fijar trabas u obstáculos que impidan que la tutela judicial esté garantizada constitucionalmente ${ }^{3}$. Aun cuando no será materia de este estudio aunque sí en posteriores, merece consideración la sentencia del

asegurador en relación en el principio de exclusividad jurisdiccional establecido por el art. 117.3 CE debido a que se estaría supeditando el ejercicio del derecho a la tutela judicial efectiva de una de las partes al consentimiento de la otra, lo que quebrantaría la esencia misma tanto de la tutela judicial como del arbitraje. En los mismos términos se pronuncia el Fiscal General del Estado al considerar que se está produciendo la imposición del arbitraje a una de las partes lo que contraviene el derecho a la tutela judicial efectiva. Sorprende, sin embargo la alegación del Abogado del Estado que, desconociendo a nuestro juicio la esencia del ensamblaje del arbitraje a nuestro texto constitucional, considera que el precepto que se pretende impugnar es perfectamente adecuado a nuestra Constitución por cuanto el derecho del art 24 es un derecho de configuración legal en el que incide el legislador comunitario al tener competencias sobre esta materia. Sin considerar que el laudo arbitral cierra la puerta a la jurisdicción salvo recurso de anulación del laudo, por lo que quedaría indefenso la parte que no apostó por el arbitraje, sin opción a que un órgano judicial pueda conocer la controversia.

3 Vid. STC 17/2008, de 31 de enero (Fundamento Jurídico 3) 
Tribunal Europeo de Derechos Humanos de 2 de octubre en los casos Pechstein y Mutu c. Suiza (apelaciones n. ${ }^{\circ} 40575 / 10$ y 67474/10 respectivamente), que versa en esencia sobre los procedimientos ante el Tribunal de Arbitraje Deportivo y su compatibilidad con el artículo 6 del Convenio Europeo de Derechos Humanos ${ }^{4}$.

En estas páginas vamos a intentar poner luz sobre esos efectos colaterales. No obstante, sí queremos poner de relieve, desde el inicio, que todo lo que hemos indicado hasta ahora en relación a los «riesgos» del arbitraje no significa que no lo defendamos como medio óptimo de resolución de litigios. Nos parece que es muy adecuado. Ahora bien, no siempre se tiene toda la información y, en muchas ocasiones, parece que se confunde el arbitraje con la mediación o la conciliación que son figuras similares en cuanto a que un tercero es llamado a resolver un litigio, pero diferentes en cuanto a los efectos de la solución propuesta por el tercero (efectos de cosa juzgada o no). Así pues, mientras que el arbitraje tiene una implicación constitucional, no la tiene la mediación o la conciliación porque el uso de esta forma de resolución de litigios no cierra el acceso a la Administración de Justicia.

\section{LA ESENCIA DEL ARBITRAJE DESDE EL PRISMA DEL DERECHO CONSTITUCIONAL}

Aun cuando la tutela judicial efectiva es administrada, según el art. 24 CE, por jueces y Tribunales que integran el poder Judicial, históricamente la propia jurisdicción apareció revestida de un carácter arbitral que ha condicionado la evolución de la misma ${ }^{5}$. En el arbitraje se pone en contacto la siempre delicada relación entre el poder público y los particulares ${ }^{6}$, porque es una

${ }^{4}$ Sobre derecho a un juicio equitativo y justo. Los recurrentes, la patinadora alemana Claudia Pechstein y el ex futbolista Adrian Mutu de nacionalidad rumana acudieron -de forma separada- al TEDH con el objeto de impugnar la validez de los laudos fallados en su contra por el TAS, tras haber acudido previamente y sin éxito ante el Tribunal Federal Suizo, cuestionando la independencia e imparcialidad del Tribunal arbitral y la naturaleza del sometimiento al arbitraje forzado del TAS, alegando que sus derechos a un juicio justo, en el sentido del Artículo 6 del CEDH, habían sido vulnerados. Ha entendido el Tribunal que sí hubo una violación del este precepto en la medida de que los procedimientos ante el TAS relacionados con sanciones sobre dopaje no se celebraron en público. Es decir, por ausencia de audiencia pública. Por otro lado sostiene que aceptación de la jurisdicción del TAS por medio de cláusula de sumisión obligatoria debe entenderse como un arbitraje «forzado» en el sentido de la jurisprudencia del TEDH. Si bien, a pesar de la calificación del arbitraje forzado, lo relevante para el TEDH es que dicho arbitraje ofrezca todas las garantías de un proceso justo, conforme a lo previsto en el Artículo 6 del CEDH.

5 García-Pita y Lastres 2010, 48-57

${ }^{6}$ Vid., Guasp Delgado 1956 
institución cuyo fundamento se encuentra en la autonomía de la voluntad de los individuos que buscan resolver sus controversias de forma más eficaz, reservada, rápida, económica. Para ello recurren a terceros privados que resuelven mediante laudo. Laudo que, al igual que una sentencia judicial, tiene efectos de cosa juzgada. La elección por esa forma de justicia alternativa no impide la intervención del Estado defendiendo siempre el interés público. Esa intervención del Estado viene delimitada por los límites en que actúa esa autonomía de la voluntad. También interviene a través de los órganos de la jurisdicción ordinaria, para revisar el laudo y ordenar su ejecutabilidad o ejecución forzosa si las partes voluntariamente no cumplen con el contenido del mismo ${ }^{7}$. Como aspectos fundamentales del arbitraje a la luz de nuestro texto constitucional podemos indicar:

- Carácter estatal de la Ley de Arbitraje al tratarse de una materia sobre la que tiene competencia exclusiva el Estado (art. 149.1.6 CE) de acuerdo con la STC 15/1989 de 26 de enero sobre la Ley de Defensa de Consumidores y Usuarios. Destaca también la STC 62/1991, de 22 de marzo que insiste en el arbitraje como equivalente jurisdiccional para justificar la competencia exclusiva del Estado en su regulación frente a las Comunidades Autónomas ${ }^{8}$. Se reitera en el argumento de que el arbitraje en cuanto a «equivalente jurisdiccional» es legislación procesal y, en consecuencia, competencia exclusiva del Estado.

- El principio de autonomía de la voluntad para someter controversias al arbitraje sin que ello vulnere el derecho a la tutela judicial efectiva del art. 24 CE (SSTC 11/1981, 212/1991 o 174/1995). La renuncia a la tutela judicial debe ser explícita, clara e inequívoca. De esta forma es contrario al art. $24 \mathrm{CE}$ la imposición obligatoria e imperativa del sometimiento al arbitraje ${ }^{9}$. Esto es así porque el control judicial sobre el laudo previsto en la Ley de Arbitraje se limita a garantías formales o aspectos meramente externos sin alcanzar el fondo del asunto sometido

7 Vid., González Soria 2006

${ }^{8}$ FJ $5^{\mathrm{a}}$ «... no cabe duda que el establecimiento de un sistema de arbitraje, como dijimos en la STC 15/1989, F.J. 9 b, es materia atribuida a la competencia del Estado por los títulos competenciales del art. 149.1, 5 y 6, pues, siendo el arbitraje un «equivalente jurisdiccional», mediante el cual las partes pueden obtener los mismos objetivos que con la jurisdicción civil (esto es, la obtención de una decisión que ponga fin al conflicto con todos los efectos de la cosa juzgada), es evidente que la creación de órganos de naturaleza arbitral y el establecimiento de dicho procedimiento heterocompositivo es materia propia de la legislación procesal civil...»

9 Vid., STC 174/1995, de 23 de noviembre, Carazo Liébana, María José 1996, $1305-1322$ 
a arbitraje ${ }^{10}$. Es tal la importancia de la voluntariedad en el arbitraje que, en relación a la declinatoria de jurisdicción para el caso de que se alegue la existencia de un arbitraje en un litigio judicial ya iniciado (arts. 11 de la Ley de Arbitraje y 39 y 63.1 de la Ley de Enjuiciamiento Civil), no se establece limitación alguna del ámbito del enjuiciamiento por el juez de su propia jurisdicción (principio kompetez-Kompetez). Ello implica que el órgano judicial va a hacer un enjuiciamiento sobre la validez y eficacia del convenio arbitral y sobre la inclusión de las cuestiones objeto de la demanda en el ámbito de la materia arbitrable. No se limita pues a una comprobación superficial de la existencia del convenio arbitral en caso de que exista ${ }^{11}$

- Arbitrabilidad del objeto de la controversia como condición indispensable para que el arbitraje sea constitucional.

- Cumplimiento en el procedimiento arbitral de una serie de garantías como son la igualdad de las partes, la audiencia, contradicción, prueba y motivación del laudo para su plena compatibilidad constitucional con el art. 24.1 de la CE.

- El laudo arbitral firme tiene efectos de cosa juzgada al igual que una sentencia judicial (SSTC 43/1988,15/1989 y 62/1991).

Sin duda, el arbitraje es una institución que interesa al constitucionalista por varias razones que intentaremos resumir en las líneas que siguen. Interesa, en primer lugar, porque el arbitraje está anclado en la libertad de las partes de someter la decisión de sus controversias a una institución arbitral siempre que éstas sean disponibles. Libertad que consagra la Constitución en el art. 1.1 cuando establece como valores superiores del Ordenamiento Jurídico la libertad junto con la igualdad, la justicia y el pluralismo político ${ }^{12}$. De esta forma, se puede afirmar que no es constitucional el arbitraje incluido en un contrato de adhesión, tampoco lo es el arbitraje obligatorio (tal como tendremos ocasión de defender en páginas sucesivas). Pero incluso nos atrevemos a decir que debiera ser igualmente inconstitucional aquel en el que, sin darse los supuestos anteriores, se pudiera demostrar que alguna de las partes desconocía o no tenía información suficiente del alcance de la firma del convenio arbitral.

${ }_{10}$ Vid., Sentencia 119/2014 de 16 de julio (FJ 5) y STC 8/2015, de 22 de enero (FJ 5)

11 Vid., STS Sala de lo civil de 27 de junio de 2017, fundamento Jurídico Tercero

12 Vid. al respecto Cruz Villalón 2007, 15-26 quien sostiene que los medios alternativos de resolución de controversias tienen una pluralidad de puntos de contacto con la Constitución. Concretamente el arbitraje privado tiene encaje en la parte dogmática de la Constitución en cuanto al principio de Libertad consagrado como valor superior del Ordenamiento Jurídico (art. 1.1 CE) 
En segundo lugar, interesa porque el laudo arbitral tiene la misma eficacia de cosa juzgada que una sentencia judicial. Ello implica inexorablemente que las garantías procesales del art. $24 \mathrm{CE}$ sean aplicables, aun con cierta flexibilidad; pero que sean aplicadas también al procedimiento arbitral, el cual se alza como un verdadero procedimiento.

No obstante lo anterior, no debemos olvidar que el árbitro no goza de potestas por lo que necesitará el auxilio judicial para la ejecución del laudo en caso de que las partes voluntariamente no lo hagan. Ello supone que la interacción entre los órganos judiciales y el árbitro deberían ser continuas. No son instituciones que intervienen de forma paralela sin que en ningún momento se encuentren. Todo lo contrario, hay o debe haber una auténtica colaboración y auxilio entre los jueces y los árbitros. En definitiva, ambos coadyuvan para la correcta administración de justicia, si bien con procedimientos diferentes.

Son muchas las cuestiones que suscita la conexión del arbitraje al derecho a la tutela efectiva desde una perspectiva constitucional, habida cuenta de que el árbitro, no lo olvidemos, debe aplicar la Constitución como norma suprema. Afirmar que el arbitraje está exento de las garantías recogidas en la Constitución, es una afirmación totalmente errónea porque la facultad de las partes de escoger el procedimiento o el camino que se debe seguir para la resolución de sus controversias, nunca debe suponer la inaplicación o vulneración de la Constitución. La cuestión radica, y a ello le vamos a dedicar las sucesivas páginas, en cómo se ensambla el proceso arbitral con las garantías constitucionales. Y en este ensamble hay un concepto básico que es el orden público o el cumplimiento de los derechos y libertades recogidos en la Constitución. De esta manera el árbitro nunca al laudar podrá vulnerar la Constitución so pena de anulación del laudo por el número f) del art. 41.1 de la Ley de Arbitraje.

Art. 41 Ley 60/2003, de 23 de diciembre de Arbitraje

1. «El laudo sólo podrá ser anulado cuando la parte que solicita la anulación alegue y pruebe:

...f) Que el laudo es contrario al orden público»

Si hemos hablado de la esencia del arbitraje en el Derecho constitucional pasaremos a analizar, de forma más concreta, cómo se produce su ensamble en nuestra Constitución. En qué preceptos podemos encajar el arbitraje dado que, como hemos dicho más arriba, no hay alusión explícita al mismo.

\section{PRECEPTOS CONSTITUCIONALES APLICABLES AL USO DEL ARBITRAJE}

La Constitución de 1978 no hace mención expresa del derecho al arbitraje. El lector de esta líneas puede plantearse si realmente existe un 
«derecho» al arbitraje. Para comenzar no trataremos tanto de dilucidar si existe como derecho. Lo que parece indubitado es que se acepta comúnmente, tanto por la doctrina como por la jurisprudencia, la viabilidad del arbitraje en nuestro texto constitucional. Hay pues una suerte de reconocimiento tácito al sometimiento de las controversias al arbitraje. Parece obvio que el art. $24 \mathrm{CE}$, en la regulación de la tutela judicial efectiva, se está refiriendo al derecho de acceso a la jurisdicción (apartado 1) y a las garantías procesales constitucionales (apartado dos) ¿Cabría aplicar las garantías constitucionales procesales al procedimiento arbitral y así entender que el reconocimiento tácito se encuentra en este precepto?

Nuestra pretensión es poner el acento en las garantías constitucionales o legales del procedimiento arbitral. Es decir, si el arbitraje es un auténtico equivalente jurisdiccional, parece lógico que los árbitros deban aplicar las garantías procesales constitucionales del art. 24 de la Constitución, convirtiéndose entonces en derechos procesales fundamentales que los particulares podrían reclamar al árbitro a través de un recurso de amparo. Por el contrario, si la naturaleza del arbitraje es meramente contractual y las garantías del procedimiento deriva única y exclusivamente de la Ley de Arbitraje (2003) entonces los particulares nunca podrían aducir lesión de los derechos procesales constitucionales del art. 24 de la CE, simple y llanamente porque las garantías del proceso arbitral son legales y no constitucionales. En esta última línea encontramos el Auto del TC 701/1988 Sección Primera, Sala Primera $^{13}$ en el que se desmarca de forma clara y contundente de la aplicación de las garantías del art. 24 de la $\mathrm{CE}$ a un arbitraje de equidad señalando textualmente que «para resolver el presente recurso de amparo constitucional, ha de señalarse, ante todo, que el derecho a la tutela judicial efectiva que reconoce y consagra el art. 24 de la Constitución se refiere a una actividad prestacional del Estado, que es la prestación de actividad jurisdiccional de Jueces y Tribunales, es decir, por los órganos jurisdiccionales del Estado, integrados en el Poder Judicial, habiendo de destacarse asimismo que el recurso de amparo constitucional se da contra los actos de los poderes públicos que lesionan los derechos fundamentales».(El subrayado es nuestro).

En esta tesis se haya la STC 9/2005, de 17 de enero de la Sala Primera que resuelve un recurso de amparo promovido frente a un laudo arbitral en cuyo fundamento quinto se indica de forma muy explícita que el recurso de amparo ante el TC sólo es susceptible de promoverse cuando la infracción

${ }^{13}$ FJ Primero...»Aunque pudiera admitirse con algún sector doctrinal que la actividad de los árbitros de Derecho privado es una actividad propiamente jurisdiccional, en la medida en que produce efectos de cosa juzgada, de ello no deriva necesariamente su sumisión a los preceptos constitucionales,...» 
del derecho fundamental deriva única y exclusivamente de la acción de los órganos de la jurisdicción, nunca de la actuación del árbitro. En ese sentido el laudo arbitral es ajeno a la actuación del $\mathrm{TC}^{14}$. Así pues las garantías del proceso arbitral proceden del ámbito de la legalidad ordinaria (de la Ley de Arbitraje) por lo que estos derechos no tienen la categoría de Derechos Fundamentales. Señala Cruz Villalón que la primera explicación que parece surgir de esta doctrina es que los derechos fundamentales están ligados al ejercicio de la potestad jurisdiccional de forma que no pueden ser vulnerados por nadie que no fuese titular de esta potestad pública ${ }^{15}$. Esta hipótesis tiene varios aspectos susceptibles de ser refutados. Concretamente, la STC 9/2005, de 17 de enero, ya señalada, cuando excluye de forma clara el arbitraje del control constitucional parece desconocer algunos aspectos de relevancia:

Primero, si se reconoce que un particular puede vulnerar un derecho fundamental (libertad de expresión, igualdad...) no entendemos por qué los árbitros no pueden vulnerar el derecho a la tutela judicial efectiva, máxime cuando el Ordenamiento jurídico les permite tomar decisiones en forma de laudo con efectos de cosa juzgada, igual que una sentencia judicial.

Segundo, las garantías del art. 24 CE forman parte del orden público procesal que se eleva como causa de anulación del laudo arbitral por la vía del art. 41.1.f) de la Ley de Arbitraje y, en consecuencia, la vulneración de las garantías de la tutela efectiva son susceptibles de recurso de anulación en sede jurisdiccional.

Tercero, si el arbitraje estuviera exento de la garantía constitucional del art. $24 \mathrm{CE}$ se produciría una quiebra del sistema constitucional de justicia. No queremos señalar que las garantías de la tutela judicial efectiva operen en igual intensidad y extensión en el arbitraje. La configuración legal de uno y otro son diferentes pero ello no implica que el derecho fundamental desaparezca absolutamente cuando se está sustituyendo un proceso (el judicial) por otro (el arbitral).

Cuarto, parece obvio que cuando se acude en amparo ante el TC se hace, no en relación al laudo arbitral directamente, sino impugnando la sentencia judicial que ha resuelto sobre el recurso de anulación del laudo. Así pues, no es el laudo lo que se impugna sino la sentencia judicial resultante de la impugnación del laudo. Ocurre una situación muy similar a cuando un

${ }^{14}$ Fundamento Jurídico $5^{\circ}$ «... la imparcialidad del árbitro y la prohibición de indefensión en el arbitraje no son garantías derivadas - con el carácter de derechos fundamentales-del art. 24 CE, cuyas exigencias sólo rigen, en lo que atañe ahora a las concretas alegaciones que se están examinando, para el proceso-actuaciones jurisdiccionales-en el que se pretende la anulación del Laudo y para el órgano judicial que lo resuelve...»

15 Vid., Cruz Villalón 2007, 25 
particular vulnera un derecho fundamental y se recurre en amparo, no la vulneración propiamente dicha del particular, sino la resolución judicial firme que ha resuelto la violación de ese derecho fundamental.

Así pues, entendemos que con la STC 9/2005 y otras se está confundiendo la posibilidad de las partes de elegir el procedimiento por el cual se van a resolver sus controversias, con la total desaparición de este derecho fundamental en sede arbitral. Entendemos, por el contrario, que el art. $24 \mathrm{CE}$ rige también en el procedimiento arbitral aunque atemperado por las peculiaridades del arbitraje frente al proceso judicial, tal como procedemos a analizar en el siguiente apartado.

\section{TUTELA JUDICIAL EFECTIVA VERSUS TUTELA ARBITRAL EFECTIVA}

Queremos comenzar aludiendo a que la tutela judicial efectiva se configura - como la mayor parte de los Derechos Fundamentales- como un derecho de configuración legal. Esto es, el contenido esencial del derecho no va a quedar delimitado sólo por su enunciado constitucional, sino que se concreta y determina definitivamente por la normativa legal que lo desarrolla. Ahora bien, que sea un derecho de configuración legal no implica, tal como ha señalado el TC en múltiples sentencias, que se pueda desnaturalizar imponiendo trabas que hagan difícil o incluso imposible el acceso a los tribunales. El derecho fundamental a la tutela judicial efectiva debe ser interpretado siempre de manera que los requisitos procedimentales establecidos en la Ley no lleguen a restringir u obstaculizar de forma injustificada las posibilidades para acceder al proceso con la finalidad de que sean conocidas y resueltas las pretensiones que se someten al órgano judicial ${ }^{16}$. Creemos necesario partir de esta hipótesis de trabajo para situarnos después en la problemática que presenta la tutela arbitral y sus posibles soluciones.

No se nos escapa que el proceso judicial surge en el momento histórico en el que el poder público decide prohibir el uso de la fuerza para que los ciudadanos resuelvan sus diferencias; o lo que coloquialmente se dice que cada uno «se tome la justicia por su mano». Se pasa de la autotutela de los derechos subjetivos a la heterocomposición o tutela por un tercero, con la especialidad, frente a otros mecanismos de resolución de controversias, que ese tercero cuando toma la decisión que corresponda, su solución tiene efectos frente a todos, no sólo frente a las partes en conflicto. Y aquí podemos hablar de los dos mecanismos que aparecen conexos desde el principio: el arbitraje y la tutela judicial y el común denominador de ambos es lo que denominaremos en

16 Ejemplo, la Sentencia TC 168/2003, de 29 de septiembre FJ $2^{\circ}$. Se puede consultar un extracto de todas ellas en Ruiz-Rico Ruiz e Carazo Liébana 2013 
adelante tutela efectiva que englobaría tanto la tutela judicial como la tutela arbitral. La diferencia entre ambas figuras radica en los sujetos que administran justicia (jueces/árbitros), en el proceso que se sigue (proceso judicial/procedimiento arbitral) y en la libre disposición o no de la controversia. Se asemejan en el efecto de cosa juzgada de la resolución judicial y del laudo arbitral y, en nuestra hipótesis de trabajo, en la subsunción de ambas figuras a las garantías constitucionales procesales. Nos estamos refiriendo a las garantías del derecho de tutela efectiva que reconoce el art. 24 de la CE. En definitiva, se trata de diferentes manifestaciones de un mismo fenómeno que resumiendo podría ser el que sigue «el reconocimiento de la posibilidad que atesoran los ciudadanos de instar a un tercero la resolución de conflictos en los que se hallen involucrados, ante la prohibición jurídica que pesa sobre ellos de que los resuelvan por si mismos arbitrariamente o mediante el uso de la fuerza» ${ }^{17}$.

Éste es nuestro punto de partida. La heterocomposición de conflictos. A partir de aquí trataremos de esbozar una hipótesis que, adelantamos, consiste en reafirmar la aplicación de los derechos que integran la tutela judicial efectiva al arbitraje. Y esta teoría tiene su fundamento en el art. 41 de la Ley de Arbitraje que prevé como causa de anulación del laudo, la infracción del orden público. Partimos también de la doctrina del TC, según la cual por orden público debe entenderse los derechos fundamentales y libertades públicas reconocidos en la Constitución. Así pues, la tesis parece lógica, los ciudadanos deben tener plenas garantías de aplicación de los derechos fundamentales con independencia de que opten por el proceso judicial o por el procedimiento arbitral en materias de libre disposición. El proceso es el camino y la solución -en forma de sentencia o laudo- es la meta. En el camino y en la meta deberá respetarse la Constitución siempre. No cabe argumentar que las partes han renunciado a la aplicación de la Constitución al optar por el procedimiento arbitral. Para un constitucionalista lo anterior es una aberración pues la superioridad de la norma suprema quedaría condicionada a la voluntad de los sujetos. En base a lo anterior procedemos en adelante a esgrimir los distintos argumentos que nos lleven a la conclusión anteriormente adelantada.

El artículo 24 de la Constitución española (CE) ha incorporado un catálogo de derechos constitucionales de naturaleza jurisdiccional o procesal, cuya aplicación casuística por el Tribunal Constitucional ha producido una profunda y progresiva modificación de las normas legislativas y la interpretación judicial sobre los diferentes procedimientos jurisdiccionales diseñados en el ordenamiento jurídico español. Esa eficacia transformadora se

17 Vid., Garberí Llobregat 2008 
explica en buena medida por la calidad normativa con que han sido enunciados por la norma fundamental, en cuanto de derechos subjetivos que están dotados de la doble condición de exigibilidad e inmediatez con que se imponen inevitablemente en la práctica procesal de cualquier órgano judicial ${ }^{18}$.

El derecho fundamental a la tutela judicial efectiva debe ser interpretado siempre de manera que los requisitos procedimentales establecidos en la Ley no lleguen a restringir u obstaculizar de forma injustificada las posibilidades para acceder al proceso con la finalidad de que sean conocidas y resueltas las pretensiones que se someten al órgano judicial. El arbitraje es una institución compatible con la Constitución y con el derecho de acceso a la justicia. Aunque no debe hacerse una traslación automática entre las garantías del procedimiento arbitral y las derivadas del artículo $24 \mathrm{CE}^{19}$. Ahora bien, el que no haya una traslación automática de las garantías del art. $24 \mathrm{CE}$ no implica que se nieguen éstas, siempre que sean compatibles con la naturaleza del arbitraje. Aquí reproducimos las palabras del TC en el Auto TC 259/1993, de 20 de julio FJ 1 al señalar entre otras cuestiones que.

«...La función que ejerce el árbitro es para-jurisdiccional o cuasi-jurisdiccional y en ese "casi» está el quid de la cuestión. Efectivamente, la inexistencia de jurisdicción en sentido propio se traduce en la carencia de potestas o poder. El árbitro, que no nos puede plantear una cuestión de inconstitucionalidad por estar reservada a los órganos judiciales (art. 163 CE), ni tampoco está legitimado para formular cuestiones prejudiciales ante el Tribunal de Justicia de la Comunidad Europea, por no ser órgano jurisdiccional...»

En las líneas que siguen mantenemos como base de nuestra teoría que efectivamente el árbitro no es un juez. Ahora bien, ello no es óbice para que se respeten en el procedimiento arbitral las garantías básicas de la tutela efectiva en relación al principio de igualdad o al derecho a no sufrir indefensión. Lo argumentamos por la realidad fáctica de la fuerza de cosa juzgada del laudo arbitral, por el carácter de derecho fundamental de la tutela efectiva y, en consecuencia, por la superioridad de la Constitución como norma suprema por encima de la ley. También lo argumentamos por la realidad de que el juez no es ajeno al arbitraje sino que está íntimamente relacionado con él, tanto en cuanto a la acción de anulación del mismo como en relación a la ejecución forzosa del laudo, entre otras actuaciones. Y existe un apartado f) en el art.

18 Vid., Ruiz-Rico Ruiz e Carazo Liébana 2013

19 En consecuencia y, por una serie de motivos -claramente expresados por la jurisprudencia constitucional-, no debe extenderse analógicamente el ámbito del derecho a la tutela judicial efectiva a la actividad arbitral. Traemos a colación en este punto la STC 174/1995, de 23 de noviembre FJ 3 la STC 176/1996, de 11 de noviembre FJ 4. Por su parte la STC 13/1997, de 27 de enero, FJ 2 
41.1 de la LA (ya lo hemos reproducido más arriba) que es el que vincula directamente el derecho a la tutela efectiva con el arbitraje al establecer como causa de anulación del laudo la infracción del orden público.

Algunos de los derechos que, resumiendo la doctrina del TC, engloba la tutela judicial efectiva y que pueden ser trasladados al arbitraje son los que siguen:

\section{El derecho a obtener de los tribunales un pronunciamiento fundado en el Derecho objetivo y a la motivación de la resolución judicial}

Para la jurisprudencia constitucional, la motivación de la resolución judicial comporta la posibilidad de reconocer lo que se denomina el «proceso lógico-jurídico» seguido por el órgano judicial hasta la elaboración del fallo. Desde esta perspectiva se van a considerar resoluciones suficientemente motivadas aquellas en la se exponen las reglas sustantivas y procesales utilizadas en el litigio, así como los instrumentos probatorios y la valoración que se hace de ellos por el tribunal; sin que pueda representar una conculcación del derecho fundamental la explicación sucinta y hasta «estereotipada» -a sensu contrario y en todo caso, no exhaustiva ni pormenorizada- de los razonamientos que se han empleado en la solución del caso.

¿Es aplicable esta doctrina al arbitraje? Si el arbitraje es de derecho ¿existe un derecho fundamental nacido del art. $24 \mathrm{CE}$ y susceptible de esgrimirse como causa de anulación del laudo arbitral si el árbitro no fundamenta adecuadamente y conforme a derecho su resolución? El art. 37.4 de la Ley de Arbitraje dispone que

«El laudo deberá ser motivado, a menos que las partes hayan convenido otra cosa o que se trate de un laudo pronunciado en los términos convenidos por las partes conforme al artículo anterior».

Precisamente una de las modificaciones operadas con la vigente Ley de Arbitraje frente a la anterior Ley 36/1988, de 5 de diciembre se encuentra la exigencia de motivación del laudo, salvo acuerdo contrario de las partes. Así pues se da un paso más acercando la institución arbitral a la jurisdiccional ${ }^{20}$.

La Sentencia de la Audiencia Provincial de Tarragona de 28 de enero de 2003 declara que «la motivación del laudo en el arbitraje de derecho es una exigencia legal y forma parte del derecho a la tutela judicial efectiva del art. 24.1 de la Constitución, y por tanto, es parte integrante del concepto jurídico de orden público, en la forma en que ha sido interpretado por el Tribunal

${ }^{20}$ Vid., Marcos Francisco 2011, 1943 
Constitucional como aquel que exige el respeto a los derechos fundamentales y libertades públicas» ${ }^{21}$.

Así llegamos a la consideración de que la falta de motivación del laudo arbitral supone una vulneración del derecho a la tutela efectiva del art. $24 \mathrm{CE}$ y, por ende, del orden público conforme al art. 41.1.F) de la Ley 60/2003 por lo que es motivo de anulación del laudo arbitral ${ }^{22}$. En este sentido destaca la sentencia del Tribunal Superior de Justicia 18/2012, de 2 de mayo en su FJ Segundo en el cual el Tribunal hace una equiparación sustantiva entre el contenido de la motivación de un laudo de derecho y el de una sentencia.

«...El laudo de Derecho emitido -basta su lectura porque reproducir no es motivar- es verdaderamente parco, porque ni contiene una valoración propia del árbitro acerca de la prueba practicada ni una acotación de los elementos de convicción tomados en consideración que nos conduzcan a ir desgranando, siquiera sea a lo largo de la inexistente argumentación, unos hechos probados, ni contiene una fundamentación jurídica más allá de la inane y genérica invocación de "los artículos 1.088, siguientes y concordantes, del vigente Código Civil (LEG 1889, 27)". En consecuencia, no es que ni siquiera se detenga a efectuar una calificación jurídica del contrato y una interpretación de su contenido para analizar el alcance de las obligaciones de las partes conforme a la técnica jurídica, es que desconocemos las razones por las que estima la demanda y desestima la excepción planteada, porque ni de la forma más somera se exponen. Hemos de concluir entonces que el laudo carece de una motivación suficiente, aunque tampoco sea precisa una argumentación exhaustiva».

De forma similar a una sentencia judicial se aplicaría al laudo, la doctrina asentada por el TC en relación al art. 120.3 «...Las sentencias serán siempre motivadas...». La línea jurisprudencial respecto a la motivación del laudo no impone que contenga un razonamiento exhaustivo y detallado con total precisión del argumentario jurídico, sino que el laudo debe ser lo suficientemente claro en la ratio decidendi que ha determinado la decisión ${ }^{23}$.

${ }^{21}$ Ello no es obstáculo que el TC haya señalado que el ámbito natural en el que se desarrolla el derecho a la tutela judicial efectiva sea la actividad jurisdiccional desarrollada por jueces y magistrados. En términos similares, vid., Sentencia Audiencia Provincial de Zaragoza n. ${ }^{\circ} 675$ de 22 de noviembre de 2002. FJ Segundo «Como consecuencia de ello el laudo a dictar había de cumplir el requisito de la motivación, que establece para dicha clase de laudos el artículo 32.2 de dicha Ley, así como también el artículo 16.2 del Real Decreto 636/1993, de 3 de Mayo (RCL 1993, 1564), lo que constituye requisito esencial del mismo, que lo diferencia del que resuelve el arbitraje de equidad, requisito in procediendo cuyo incumplimiento vicia de nulidad el laudo por resultar contrario a norma de orden público como es la que establece tal requisito.»

22 Vid., Hermosilla Martin e Rubio Escobar 2006: 489-490

23 Vid., SSTC 14/1991, 28/1994, 153/1995 y 32/1996, entre otras. 
El laudo definitivo que dicten los árbitros debe ser congruente con las pretensiones y alegaciones de las partes. Esta necesidad de congruencia se manifiesta en el art. 39.1 c) LA, que establece la posibilidad de que las partes soliciten al tribunal arbitral «... el complemento del laudo respecto de peticiones formuladas y no resueltas en él...». En los supuestos de extra petita, establece el art. $41 \mathrm{c}$ ), como motivo de anulación del laudo, «... que los árbitros hayan resuelto sobre cuestiones no sometidas a su decisión.... ${ }^{24}$.

\section{El derecho a los recursos que las leyes establezcan contra las resoluciones judiciales}

De especial trascendencia para la materialización del derecho fundamental del artículo $24 \mathrm{CE}$ ha sido la posición del TC en torno a otra cuestión clave de la tutela judicial como es el ejercicio del derecho a utilizar los instrumentos de revisión judicial. Como premisa de partida, la jurisprudencia constitucional ha considerado que el derecho a los recursos forma parte del contenido esencial de las garantías procesales reguladas en aquel precepto; si bien, no deja de introducir en este punto algunas matizaciones de considerable relieve e importancia para concebir el alcance real de ese derecho subjetivo. Ya sabemos que se diferencia entre procesos penales y no penales. En los penales el derecho a los recursos forma parte del derecho fundamental a la tutela judicial efectiva mientras que en los procesos no penales se trata de un derecho de configuración legal. Es decir, se tendrá derecho siempre y cuando el legislador así lo prevea. En lo que respecta a los procesos no penales, el derecho constitucional del art. $24 \mathrm{CE}$ sólo tiene cabida una vez se hayan establecido por la ley los requisitos y medios de impugnación necesarios para reaccionar en la vía jurisdiccional concreta contra la resolución de instancia. Esta tesis ha sido suscrita sin matices por la jurisprudencia constitucional; significa, en consecuencia, que no sólo la forma de ejercicio, sino la existencia misma del recurso no están predeterminados en la norma fundamental, sino en su configuración legislativa.

Trasladando estas garantías al arbitraje debemos señalar que efectivamente la Ley de Arbitraje actual (igual que las que la han precedido) prevé una acción de anulación del laudo arbitral por las causas y motivos que se alegan en el art. 41 de la misma. Las partes en el arbitraje tienen a su disposición un mecanismo impugnatorio que les permite luchar contra el laudo dictado por los árbitros a través de esta acción de anulación. En este sentido la notificación del laudo abrirá la posibilidad de la parte interesada de ejercer la acción de anulación en defensa de sus pretensiones.

${ }^{24}$ Vid., Cremades 2006,185-220 


\section{El derecho a la ejecución de las resoluciones judiciales}

El derecho a la tutela judicial efectiva del art. 24.1 CE garantiza la eficacia de la cosa juzgada material. En su aspecto negativo, excluye nuevos pronunciamientos judiciales con idéntico objeto procesal al resuelto por resolución judicial firme. En su aspecto positivo o prejudicial, impide que los Tribunales puedan desconocer las situaciones declaradas o reconocidas en resolución judicial firme.

Es aceptado que forma parte del derecho a la tutela judicial efectiva que el fallo judicial se cumpla, de manera que el ciudadano que ha obtenido la sentencia vea satisfecho su derecho y, por consiguiente, que las sentencias y decisiones judiciales no se conviertan en meras declaraciones sin fuerza ejecutiva. Así pues, el derecho a la tutela judicial efectiva comprende el derecho a la ejecución de las sentencias en sus propios términos, respetando el denominado efecto de cosa juzgada material ${ }^{25}$.

En relación al arbitraje el laudo necesita para su ejecución forzosa el auxilio judicial. Su equiparación es plena en relación a la sentencia judicial. La ejecución forzosa del laudo arbitral se regula en los arts. 44 y 45 de la Ley 60/2003 y en la Ley de Enjuiciamiento Civil. Una vez firme el laudo, el apartado 2 del art. 522 de la LEC permite a quienes hayan sido parte en el proceso «o acrediten interés directo y legítimo pedir al Tribunal las actuaciones precisas para la eficacia» del laudo constitutivo y para «vencer eventuales resistencias a lo que dispongan». La competencia objetiva para ordenar esas actuaciones precisas para la eficacia del laudo debería corresponder al Juzgado de Primera Instancia del lugar en que se haya dictado el laudo de conformidad con el apartado 2 del art. 545 de la LEC cuya aplicación analógica resulta procedente a estos efectos ${ }^{26}$.

\section{El derecho a la inmodificabilidad de las resoluciones judiciales firmes fuera de los cauces legalmente establecidos al efecto}

El principio de intangibilidad o invariabilidad del fallo es una consecuencia del principio de seguridad jurídica y del derecho a la tutela judicial efectiva $^{27}$. Pues bien, si el laudo tiene los mismos efectos de cosa juzgada que una sentencia, nos parece obvio que se trasladen todas las garantías del derecho a la tutela al laudo arbitral. La STC 288/1993, de 4 de octubre aplica al laudo el principio de inmodificabilidad de las resoluciones judiciales en su FJ Tercero

25 Vid., STC 135/1994 de 9 mayo, FJ 2; STC 61/1984 de 16 mayo. FJ 1.

26 Vid., Remón Peñalver y Mendieta Grande, 2006, p. 581.

27 STC 262/2000 de 30 octubre. FJ 2 STC 55/2002 de 11 marzo FJ 2. 
«...La inalterabilidad de las decisiones judiciales firmes es también predicable, en virtud de su configuración legal, de los laudos arbitrales regulados en la Ley 36/1998. En este sentido su art. 37 establece con absoluta claridad que «el laudo arbitral firme produce efectos idénticos a la cosa juzgada. Contra el mismo sólo cabrá el recurso de revisión, conforme a lo establecido en la legislación procesal para las Sentencias judiciales firmes». Ello es conforme con la naturaleza del arbitraje, que es (STC 62/1991) "un equivalente jurisdiccional, mediante el cual las partes pueden obtener los mismos objetivos que con la jurisdicción civil, esto es, la obtención de una decisión al conflicto con todos los efectos de la cosa juzgada».

Incluso en el caso en que una decisión judicial admita un recurso extemporáneo y modifique un laudo arbitral que ya había adquirido firmeza, ello vulneraría el art. 24 de la CE.

Respecto al recurso de revisión señalar que la revisión del laudo arbitral firme, debería fundarse en alguno de los motivos del art. 510 LEC siendo de aplicación al arbitraje los números 1 ,

"cuando después de pronunciado el laudo, se recobraran u obtuvieran documentos decisivos de los que no se hubiera podido disponer por fuerza mayor o por obra de la parte en cuyo favor se hubiera dictado».

número 2

«Si el laudo hubiera recaído en virtud de documentos que al tiempo de dictarse ignoraba una de las partes haber sido declarados falsos en un proceso penal o cuya falsedad se declarara después penalmente».

y número 4

«Si el laudo se hubiera ganado injustamente en virtud de cohecho, violencia o maquinación fraudulenta».

\section{El derecho a no sufrir indefensión}

El artículo 24 de la CE regula la prohibición de indefensión, como fundamento de una obligación que tiene como destinatario a los órganos de la justicia ordinaria, quienes deben velar en todo momento para que exista un equilibro en las posibilidades de defensa de las partes que actúan en el litigio. Al mismo tiempo, y en sentido positivo, se trata de un principio desde el que se llega a configurar un derecho subjetivo que se puede hacer valer en todas las fases del procedimiento, cuando no se respeta lo que el TC ha denominado «el derecho de defensa contradictoria» (STC 13/2006). Es decir, la posibilidad de utilizar todos los mecanismos y armas procesales que otorga a los contendientes judiciales el Ordenamiento Jurídico. 
Igualmente el derecho a no sufrir indefensión se configura como una regla básica en el procedimiento arbitral. Es interpretación del TC que cuando en el procedimiento arbitral pueda probarse esa indefensión entonces el laudo podría ser anulado judicialmente por la vía del art. 41 de la Ley de Arbitraje. Aquí volvemos a ver la analogía entre el proceso judicial y el arbitral.

Un aspecto interesante nos lo ofrece la STC 174/1995, de 23 de noviembre al declarar inconstitucional el art. 38.2 de la Ley 16/1987, de 30 de julio de Ordenación de los Transportes Terrestres ${ }^{28}$ al establecer un sistema de arbitraje obligatorio que llevó a un análisis en profundidad del arbitraje. Se llega a la conclusión de que sólo procede y sólo es constitucional si existe libertad de las partes o libre autonomía de la voluntad.

Asimismo, nos parece claro que el recurso de amparo ante el TC se dirige en relación a la resolución judicial que conoce del recurso o acción de anulación del laudo y, por supuesto, no frente al laudo mismo. Si bien, a través de ese recurso de amparo contra la resolución judicial se accede, aunque de forma mediata, a un control del laudo que ya fue objeto de revisión en sede jurisdiccional.

En definitiva, con este trabajo hemos querido defender el arbitraje como método heterocompositivo de resolución de controversias totalmente coherente con la Constitución, siempre y cuando se cumplan dos premisas previas. La primera es la autonomía de la voluntad de las partes como fundamento del arbitraje. Esto es, las partes deben hacer constar de manera clara y explícita que prefieren resolver sus controversias a través de la institución arbitral.

En segundo lugar, el uso del arbitraje no puede suponer una merma de las garantías constitucionales para las partes. Piénsese que el laudo tiene efectos de cosa juzgada. Se debe garantizar los derechos fundamentales de los afectados. Estos derechos se protegen con la acción de anulación del laudo y, en caso de ser infructuoso, con un posible recurso de amparo contra la sentencia que resuelva la misma. Sólo así conseguiremos una armonía entre garantías procesales constitucionales y la extensión del arbitraje a la que estamos asistiendo en distintos ámbitos del Ordenamiento Jurídico hasta ahora ajenos al mismo.

Subrayamos nuestra defensa del arbitraje con todas sus bondades pero siempre y cuando el uso del mismo no implique menoscabar ningún derecho constitucional.

\section{BIBLIOGRAFÍA}

CARAzo LiéBAna (1996). «Sobre la constitucionalidad del arbitraje obligatorio en materia de transporte (Comentario a la Sentencia del Tribunal Constitucional de 23 de noviembre de 1995». RDM, n. ${ }^{\circ} 222$ : 1305-1322.

${ }^{28}$ Vid., Carazo Liébana, 1996. 
CRemades (2006). «El arbitraje en la doctrina Constitucional española». Revista del Círculo Peruano de Arbitraje, n. ${ }^{\circ}$ 1:185-220.

Cruz Villalón (2007). «Medios alternativos y Constitución». Anuario de la Facultad de Derecho dela Universidad Autónoma de Madrid, n. ${ }^{\circ}$ 11: 15-26.

GARBERí Llobregat (2008). El derecho a la tutela judicial efectiva en la jurisprudencia del Tribunal Constitucional. Barcelona: Bosch.

GARCÍA-PITA y LASTRES (2010). «El artículo 24 de la Constitución y el Arbitraje», El Cronista del Estado Social y Democrático de Derecho, n. ${ }^{\circ}$ 10: 48-57.

González Soria (2006). «Prólogo». Comentario a la Ley de Arbitraje, coordinado por Alberto Martin Muños y Santiago Hierro Anibarro, 9-15. Barcelona: Marcial Pons.

Guasp Delgado (1956). El arbitraje en Derecho Español. Su nueva regulación conforme a la Ley de 22 de diciembre de 1953, Barcelona: Bosch.

Hermosilla Martin e Rubio Escobar (2006). «Del pronunciamiento del laudo y de la terminación de las actuaciones arbitrales». coordinado por Alberto Martin Muños y Santiago Hierro Anibarro. Madrid-Barcelona: Pons.

MARCOS FrANCISCO (2011). «Las garantías del arbitraje tras la reciente reforma de la Ley arbitral». Actualidad Civil, n. ${ }^{\circ}$ 17: 1943.

Remón PeÑalver e Mendieta Grande (2006). «De la ejecución forzosa del laudo». coordinado por Alberto Martin Muños y Santiago Hierro Anibarro. Madrid-Barcelona: Pons.

RuIZ-Rico RuIz e CARAzo LiÉBANA (2013). El derecho a la tutela judicial efectiva. Valencia: Tirant lo Blanch. 


\title{
EL ENSAMBLAJE DEL ARBITRAJE EN LA CONSTITUCIÓN: LAGUNAS DESPUÉS DE 40 AÑOS
}

\section{The Arbitration in the Constitution: Gaps after 40 years}

\author{
María José Carazo-Liébana \\ Profesora Titular de Derecho Constitucional \\ Universidad de Jaén \\ mjcarazo@ujaen.es
}

http://dx.doi.org/10.18543/ed-67(1)-2019pp165-184

\section{Copyright}

Estudios de Deusto es una revista de acceso abierto, lo que significa que es de libre acceso en su in tegridad. Se permite su lectura, la búsqueda, descarga, distribución y reutilización legal en cualquier tipo de soporte sólo para fines no comerciales, sin la previa autorización del editor o el autor, siempre que la obra original sea debidamente citada y cualquier cambio en el original esté claramente indicado

Estudios de Deusto is an Open Access journal which means that it is free for full access, reading, search, download, distribution, and lawful reuse in any medium only for non-commercial purposes, without prior permission from the Publisher or the author; provided the original work is properly cited and any changes to the original are clearly indicated. 